\title{
Reflecting and Shaping World Views: Historical Treatments in Classification
}

\author{
by Hur-Li Lee, Kangnan Gu, Zarina Mohd Shah \\ School of Information Studies \\ University of Wisconsin-Milwaukee, USA
}

Examples of historical treatments in classification and categorization are abundant in our lives. In American pop culture, we often use decades as a framework to define, understand and interpret fashions, ideas, events, and issues. The 1960s, for example, represent to many Americans a time commonly associated with youth and rebellion and the first vivid images from the decade that come to mind include rock 'n roll music and hippies. Another example is the simple categorizations applied by the National Museum of Women in the Arts (NMWA) on their Website (http://www.nmwa.org/collection/) to organize its permanent collection into: the 16th-17th, 18th, 19th, and 20th centuries. In today’s widely used library classifications (e.g., Dewey Decimal Classification and Library of Congress Classification), historical treatments have always been a standard feature, seen throughout the schedules (e.g., 372.904 for "elementary education in the 20th century” in DDC and PN720 for "literary history in Renaissance” in LCC).

At a quick glance, historical treatments seem straightforward and uncomplicated. This apparently common-sense impression may explain why classification research has yet to provide a thorough theoretical discussion on historical treatments. This poster project has two goals: (1) to initiate a scholarly discourse on historical treatments in classification; and (2) to examine how historical treatments in various classification schemes reflect and/or shape our world views. 
Included in the poster presentation are three major components. The first component presents a summary of three methods of historical treatments common in classification: (1) the linear approach with which each event, etc., is identified as a point in time (e.g., the Great San Francisco Earthquake of 1906); (2) the arbitrary approach with which events, etc., are arranged into arbitrarily cut-out chunks of time (e.g. modern medicine in the $19^{\text {th }}$ century); and (3) the regimented approach with which a periodization framework is applied to arranging and conceptualizing events, etc. (e.g. Harlem Renaissance of the 1920s).

The second component highlights cultural influences in all three types of historical treatments. A brief review of literature in history and American political development helps identify several issues raised by scholars, including those from the postcolonial and feminist perspectives (e.g., Kelly-Gadol, 1987; Mayhew, 2005; Polsky, 2005; Wishart, 2004). For example, some point out periodization schemes as known in the United States are based mainly on the experiences of Western civilization and thus not meaningful on a global scale or coherent across the boundary lines of societies and cultures. Others criticize periodization to be intellectually restrictive for understanding history. Instances from various classifications, both universal (e.g., a library classification) and specialized (e.g., a scheme used on an organization's Web site), will be given to illustrate the points.

In the final component, the authors further deliberate on the impact of various types of historical treatments in classification on information seeking and use. Users’ diverse backgrounds and information-seeking contexts are among the factors to be considered. 


\section{References:}

Kelly-Gadol, J. (1987). Did women have a Renaissance? In R. Bridenthal, C. Koonz \& S. Stuard (Eds.), Becoming visible: Women in European history (2nd ed., pp. 175201). Boston: Houghton Mifflin.

Mayhew, D. R. (2005). Suggested guidelines for periodization. Polity, 37(4), 531-535.

Polsky, A. J. (2005). No tool is perfect: Periodization in the study of American political development. Polity, 37(4), 523-530.

Wishart, D. (2004). Period and region. Progress in Human Geography, 28(3), 305-319. 